\title{
Scaling Behaviour of Si-alloyed Steel Slabs under Reheating Conditions
}

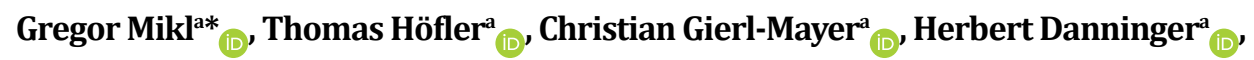 \\ Bernhard Linder $^{\mathrm{b}}$, Gerhard Angeli ${ }^{\mathrm{b}}$ \\ a TU Wien, Institute of Chemical Technologies and Analytics, Getreidemarkt 9/164-CT, 1060 Vienna, Austria

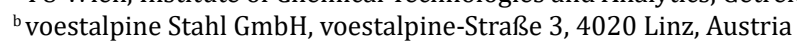 \\ *e-mail: gregor.mikl@tuwien.ac.at
}

(C) 2021 Authors. This is an open access publication, which can be used, distributed and reproduced in any medium according to the Creative Commons CC-BY 4.0 License requiring that the original work has been properly cited.

Received: 8 September 2021/Accepted: 20 October 2021/Published online: 2 November 2021.

This article is published with open access at AGH University of Science and Technology Journals.

Paper presented at the EUROMAT 2021: Cast Irons and Steel Making. September 13-17, 2021, Virtual Conference.

\begin{abstract}
Reheating of steel slabs for further processing such as hot rolling usually takes place in gas-fired pusher furnaces. Temperatures well above $1000^{\circ} \mathrm{C}$, combined with an atmosphere containing $\mathrm{H}_{2} \mathrm{O}, \mathrm{CO}_{2}$, and $\mathrm{O}_{2}$, lead to substantial oxidation of most steel grades. Newly developed advanced steels often contain significant amounts of Si. This element plays a dominant role in the scaling behaviour near the steel-scale-interface, since fayalite $\left(\mathrm{Fe}_{2} \mathrm{SiO}_{4}\right)$ forms a eutectic with wuestite $\left(\mathrm{Fe}_{1-\mathrm{x}} \mathrm{O}\right)$ that melts as low as $1177^{\circ} \mathrm{C}$. To better understand the high temperature oxidation behaviour, lab-scale trials were performed with different steel grades containing up to $3 \mathrm{wt}$ \% Si. Possible interactions of Si with other alloying elements present in the samples such as $\mathrm{Cr}, \mathrm{Mn}$ and $\mathrm{Al}$ were also of interest. The atmosphere contained $20 \% \mathrm{H}_{2} \mathrm{O}, 7 \% \mathrm{CO}_{2}$, and $3 \% \mathrm{O}_{2}$, resembling reheating conditions in pusher furnaces, and temperatures ranged from 1100 to $1240^{\circ} \mathrm{C}$. For metallographic investigation, the oxidised samples were cold mounted under vacuum using taper section angles. After preparation, the sections were examined through light microscopy, SEM/EDS, XRD, and TEM. The local distribution of the alloying elements could be mapped efficiently, and phase identification was successful in most parts. Under the applied experimental conditions, the elements of interest were present in their oxidic form either as pure or as mixed oxides. Higher Si-contents led to an increased build-up of eutectic melting phase at the steel-scale-interface at temperatures above $1177^{\circ} \mathrm{C}$, which in turn further accelerated the oxidation.
\end{abstract}

\section{Keywords:}

steel, hot rolling, oxidation, scale, alloy, $\mathrm{Si}$ oxides, $\mathrm{Fe}_{2} \mathrm{SiO}_{4}$

\section{INTRODUCTION}

Reheating of steel slabs for further processing such as hot rolling usually takes place in gas-fired pusher furnaces, where the prevailing conditions lead to substantial oxidation of most steel grades. Newly developed advanced steel grades often contain significant amounts of Si. It is an inexpensive solid solution hardener [1] and highly effective in improving the magnetic properties by reducing electric conductivity and thus decreasing eddy current losses [2]. Silicon affects the scaling behaviour, since fayalite $\left(\mathrm{Fe}_{2} \mathrm{SiO}_{4}\right)$ forms a eutectic with wuestite $\left(\mathrm{Fe}_{1-\mathrm{x}} \mathrm{O}\right)$ that melts as low as $1177^{\circ} \mathrm{C}$ [3], which will strongly enhance scaling. This happens due to accelerated transport mechanisms like an increased diffusion rate in the liquid phase. Mouayd et al. found that an increase in the Si content of a steel inhibits the scale growth at temperatures below $1177^{\circ} \mathrm{C}$ and accelerates it at higher temperatures [4]. When other alloying elements like $\mathrm{Mn}, \mathrm{Cr}$, and $\mathrm{Al}$ are present, they will still form mostly simple and uncomplex alloy element oxides with a layered arrangement at grain boundaries and intragranularly [5].

To better understand the high temperature oxidation behaviour, lab-scale trials were performed with different steel grades containing up to $3.2 \mathrm{wt}$ \% Si. Possible interactions of $\mathrm{Si}$ with other alloying elements present in the steels such as $\mathrm{Cr}, \mathrm{Mn}$ and $\mathrm{Al}$ were also of interest.

\section{MATERIALS AND METHODS}

Six steel grades with varying Si-content were used for the experiments. Their composition is shown in Table 1, where the main alloying elements are listed. 
Table 1

Steel grade composition with main alloying elements

\begin{tabular}{cccccc}
\hline \multirow{2}{*}{$\begin{array}{c}\text { Steel } \\
\text { grade }\end{array}$} & \multicolumn{5}{c}{ Concentration, wt.\% } \\
\cline { 2 - 6 } & $\mathbf{C}$ & $\mathbf{S i}$ & $\mathbf{C r}$ & $\mathbf{M n}$ & Al \\
\hline $0.2 \mathrm{Si}$ & 0.1 & 0.2 & 0.4 & 1.9 & $<0.1$ \\
\hline $0.6 \mathrm{Si}$ & 0.1 & 0.6 & 0.3 & 1.7 & $<0.1$ \\
\hline $0.8 \mathrm{Si}$ & 0.1 & 0.8 & 0.2 & 2.6 & $<0.1$ \\
\hline $1.5 \mathrm{Si}$ & 0.2 & 1.5 & $<0.1$ & 2.4 & $<0.1$ \\
\hline $1.9 \mathrm{Si}$ & $<0.1$ & 1.9 & $<0.1$ & 0.2 & $<0.1$ \\
\hline $3.2 \mathrm{Si}$ & $<0.1$ & 3.2 & $<0.1$ & 0.3 & 0.8 \\
\hline
\end{tabular}

Figure 1 describes the sample preparation procedure. Samples were cut to a size of about $10 \times 10 \times 5 \mathrm{~mm}$. Grinding of the surfaces was performed, with ultrasonic cleaning steps in isopropanol after each grit change, to a final grit of P2000. The processing atmosphere contained $20 \% \mathrm{H}_{2} \mathrm{O}, 7 \% \mathrm{CO}_{2}$, and $3 \% \mathrm{O}_{2}$, balance $\mathrm{N}_{2}$, and temperatures ranged from 1100 to $1240^{\circ} \mathrm{C}$. These conditions were chosen to mimic the reheating process in a pusher furnace. A horizontal tube furnace was used for the lab-scale experiments. The linear gas flow was set to correspond to a value of $0.6 \mathrm{~m} \cdot \mathrm{s}^{-1}$ at $1100^{\circ} \mathrm{C}$. This should have provided enough oxidising agent to prevent limitations of the reaction rate caused by insufficient gas flow. If this parameter is ignored, it will result in misleading findings [6].
Heating rate was set to $10 \mathrm{~K} \cdot \mathrm{min}^{-1}$ and the switch from an initial inert $\mathrm{Ar}$ atmosphere to the oxidising atmosphere happened at $400^{\circ} \mathrm{C}$.

The isothermal dwell time at $\mathrm{T}_{\max }$ ranged from 0 to $60 \mathrm{~min}$. Cooling took place under $\mathrm{Ar}$ and with a rate of $10 \mathrm{~K} \cdot \mathrm{min}^{-1}$. Below $700^{\circ} \mathrm{C}$, cooling became increasingly non-linear and the total cooling time was observed to be about $7 \mathrm{~h}$ during the experiments. For metallographic investigation, the oxidised samples were cold mounted under vacuum using taper section angles to enhance depth resolution [7]. After preparation, the sections were examined through light microscopy, SEM/EDS, XRD, and TEM.

\section{RESULTS AND DISCUSSION}

\subsection{Si-Influence on scaling behaviour}

The scaling behaviour changed substantially when the Si-content in the steel samples increased, which is also visible in Figure 2. Massive Si enrichment near the steel-scale interface led to the build-up of fayalite-wuestite eutectic. Mn was also present because of the complete miscibility of wuestite and $\mathrm{MnO}$.

As soon as the temperature of the specimen surpassed the eutectic point of $1177^{\circ} \mathrm{C}$, the oxidation rate increased.

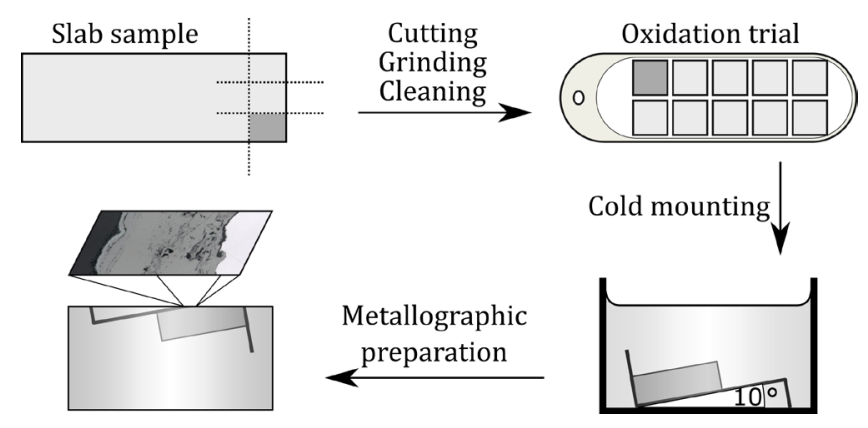

Fig. 1. Sample preparation procedure

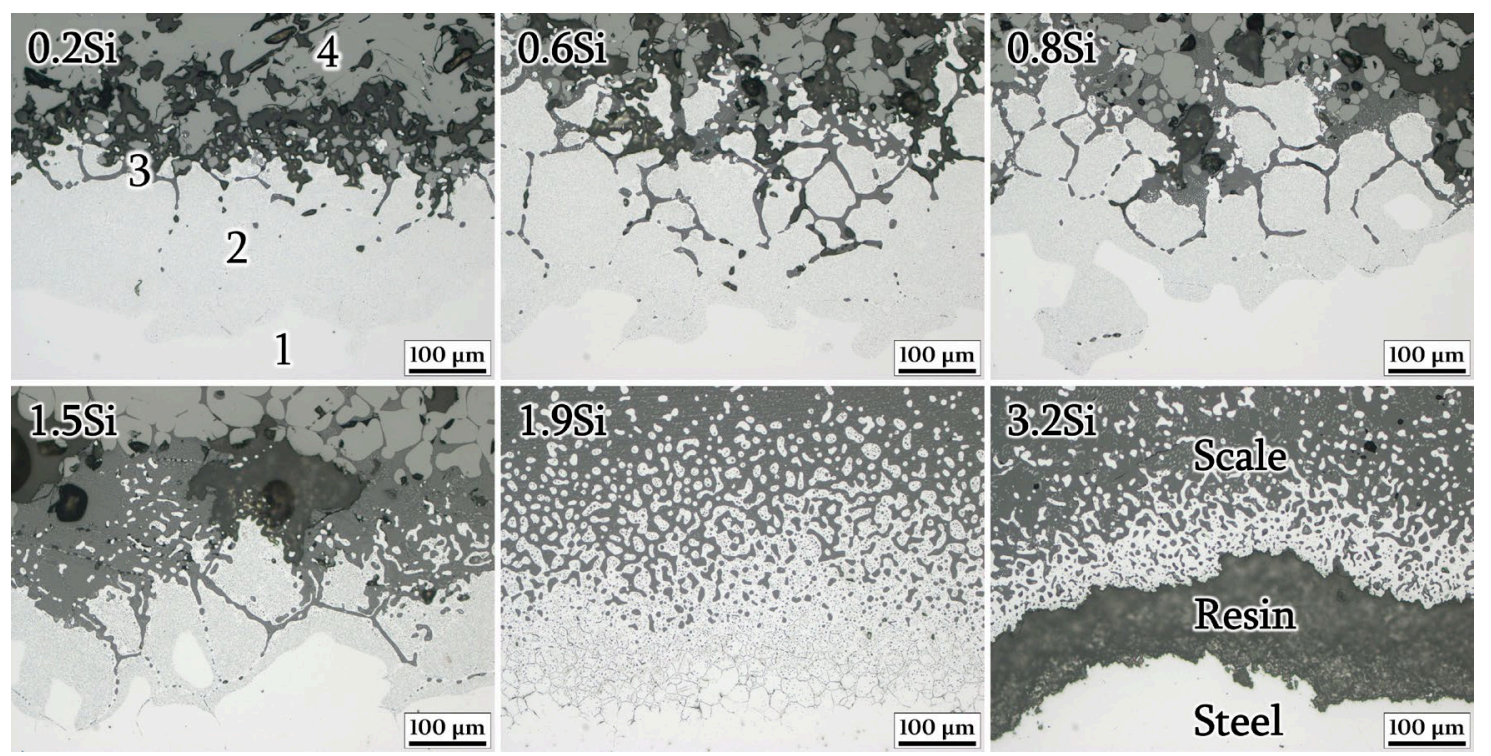

Fig. 2. $10^{\circ}$ taper sections of samples oxidised at $1200^{\circ} \mathrm{C}$ for $15 \mathrm{~min}$ with varying Si-content; steel-scale-interface with the steel side located at the bottom of the pictures; $1.9 \mathrm{Si}$ and $3.2 \mathrm{Si}$ samples had a smaller grain size prior to oxidation: 1 ) steel substrate; 2 ) area affected by internal oxidation; 3) interface, streaked by fayalite-wuestite eutectic; 4) scale, mainly composed of wuestite and magnetite 
Temperature spikes appearing during in-situ temperature measurements at the surface of the samples confirmed this. The energy release was caused by the exothermic oxidation reactions taking place near the steel-scale-interface. When enough oxidizing medium is available and the reaction is not limited by the gas phase transport, small samples may experience massive overheating. Heat cannot dissipate quickly enough, leading to a local temperature build-up significantly higher than the surrounding heating chamber $[8,9]$. Temperature control during annealing of small samples in oxidative atmospheres should thus be conducted diligently.

The liquid phase infiltrated the grain boundaries of the external scale as well as the grain boundaries near the surface of the steel substrate. Above the temperatures sufficiently high for the eutectic to melt, the oxidation mechanism did not change any further up to the maximum investigated temperature of $1240^{\circ} \mathrm{C}$.

XRD measurements performed directly at the surface of the polished taper sections confirmed the presence of wuestite and magnetite in the scale, as pictured in Figure 3. Fayalite was not detected via XRD, which could have been due to a too low concentration in the scale, a too small grain size or the absence of crystallinity. An amorphous contribution is actually visible between 10 and $30^{\circ}$. Most of the XRD peaks could be identified successfully. The confirmation of existence of fayalite was possible by registering the melting temperature of the fayalite-wuestite eutectic at $1177^{\circ} \mathrm{C}$ through temperature measurements at the sample surface during oxidation

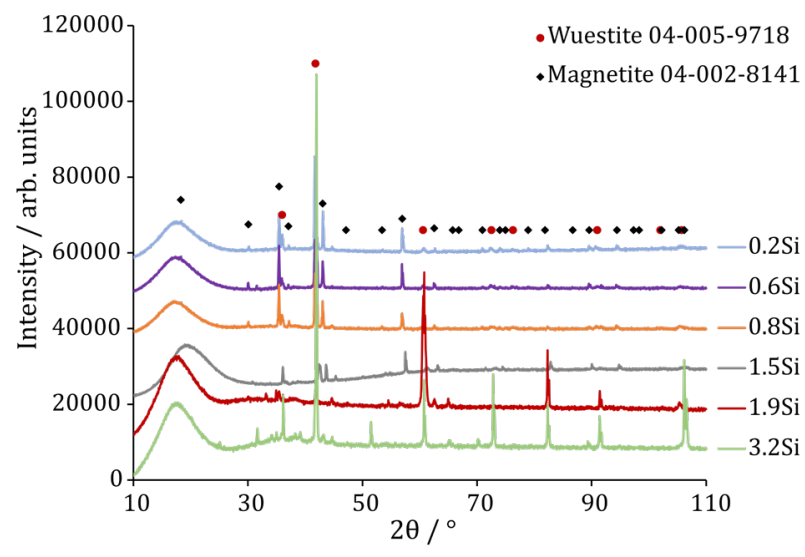

Fig. 3. XRD patterns of samples oxidised at $1180^{\circ} \mathrm{C}$ for $15 \mathrm{~min}$; wuestite and magnetite were clearly identified

\subsection{Cr-Influence on scaling behaviour}

Cr was enriched at the steel-scale interface, and after the initial detachment of the scale from the steel during oxidation it was located at the inner part of the external scale, clearly visible in Figure 4. Cr-rich oxides had formed a band held together by a Fe-Si-Mn-O binder phase.

$\mathrm{Si}$ and $\mathrm{Cr}$ did not form mixed oxides but were located next to each other. There is one report in the literature which describes that $\mathrm{Cr}_{2} \mathrm{SiO}_{4}$ was synthesized, but only at $1600^{\circ} \mathrm{C}$ and a pressure of $37 \mathrm{kbar}$ [10]. The Cr-rich oxide band did not contribute to a better bonding of scale to steel, but seemed to have promoted the opposite. No continuous Cr-oxide band formation was detected in steel grades containing less than $0.1 \mathrm{wt} \% \mathrm{Cr}$.

\subsection{Mn- and Al-Influence on scaling behaviour}

Mn exists in a variety of oxidation states and its oxides form solid solutions without miscibility gaps with major scale components like wuestite or fayalite. No specific influence on the scaling behaviour was detected that was attributable to the varying Mn content in the samples. Higher Si-enrichment correlated with higher Mn-enrichment (see Fig. 4). The strongest Mn-enrichment was measured in the grain boundaries near the reaction front, with concentrations exceeding $10 \mathrm{wt} . \%$. It is noteworthy that higher Mn concentrations will also increase the volume of the forming liquid phase at the steel-scale interface due to the excellent miscibility of the Mn- and Si-oxides present.

Al was alloyed in a concentration above $0.1 \mathrm{wt} . \%$ in the $3.2 \mathrm{Si}$ sample only ( 0.8 wt.\%). Here it caused a reduction of the melting point to the ternary eutectic $\mathrm{FeAl}_{2} \mathrm{O}_{4}-\mathrm{Fe}_{2} \mathrm{SiO}_{4}-\mathrm{Fe}_{1-\mathrm{x}} \mathrm{O}$ $\left(T_{m}=1148^{\circ} \mathrm{C}\right)$. Nevertheless, it was enriched at the reaction front of the other steel grades as well (see next section). Al can mix with $\mathrm{Si}$ in the oxide phase by forming silicates.

\subsection{The reaction front}

Every steel grade except for 3.2Si underwent internal oxidation. There is a limiting concentration of solute, in this case $\mathrm{Si}$, in the alloy, above which the outward diffusion of the solute will be rapid enough to form a continuous blocking layer and stop the internal oxidation [11]. Atkinson calculated the critical Si-concentration that would result in the prevention of internal oxidation. For around $1000^{\circ} \mathrm{C}, 2.6 \mathrm{wt} . \%$ Si should be sufficient as a prevention measure [12].

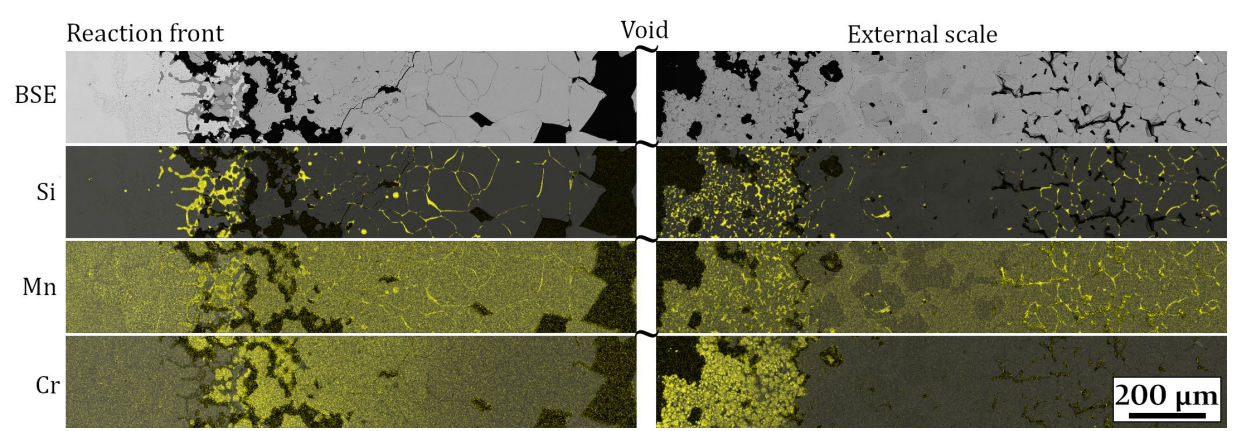

Fig. 4. EDS-mapping of a $10^{\circ}$ taper section of $0.6 \mathrm{Si}$, oxidised at $1200^{\circ} \mathrm{C}$ for $15 \mathrm{~min}$; steel-side is on the left, pronounced $\mathrm{Cr}$-enrichment at the inner part of the external scale 
a)

b)

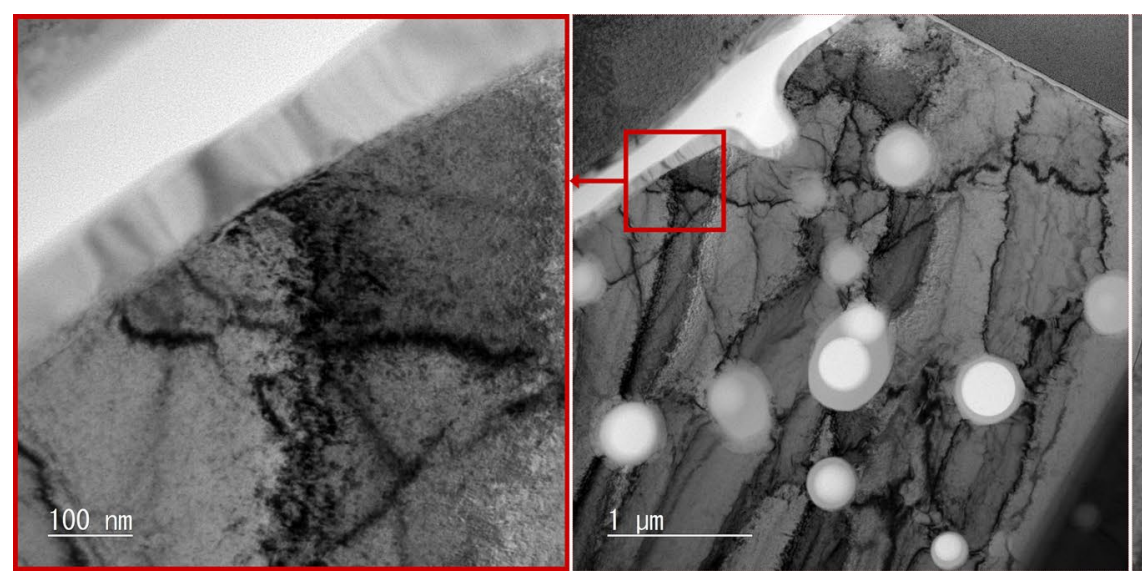

c)

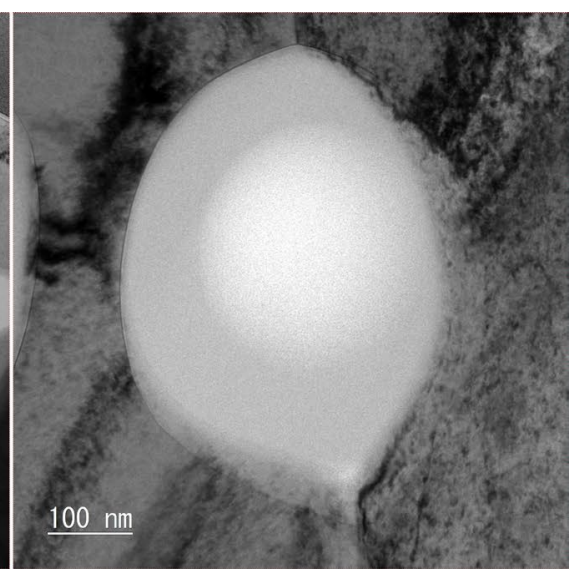

Fig. 5. TEM-images from the interface region of 1.5Si: a) oxidised grain boundary; b) overview over the FIB-lamella with oxidised grain boundary and spherical $\mathrm{SiO}_{2}$-inclusions; c) $\mathrm{SiO}_{2}$-inclusion

Oxidation at the reaction front started from the grain boundaries, consuming the grains from the outside inwards. From a thermodynamic perspective, Al should have oxidised first. Aluminium was present at the innermost tips of the oxidised grain boundaries, which confirmed this assumption. With the help of TEM and by using EELS, $\mathrm{MnO}_{2}$ and $\mathrm{SiO}_{2}$ were identified at the grain boundaries. $\mathrm{MnO}_{2}$ was located next to the metallic substrate and $\mathrm{SiO}_{2}$ followed in the centre of the grain boundaries. The spherical inclusions in the grains consisted of $\mathrm{SiO}_{2}$, shown in Figure 5. No Cr-rich phase was detected at the reaction front.

\section{CONCLUSION}

The scaling behaviour of Si-containing steels is not only influenced by Si but also by the other alloying elements such as $\mathrm{Cr}$. Small amounts (below $0.5 \mathrm{wt}$ \% $\mathrm{Cr}$ ) lead to distinct band formation that can influence the adherence of the scale to the substrate. Surpassing the melting point of the fayalite-wuestite eutectic at $1177^{\circ} \mathrm{C}$ leads to an accelerated oxidation of the steel, visible through a temperature spike at the sample surface, as the liquid phase promotes material transport. The energy release is caused by the exothermic oxidation reactions taking place in the vicinity of the steel-scale-interface.

0.2 wt.\% Si are enough for the eutectic to occur. In the presence of $0.8 \mathrm{wt} . \%$ aluminium, the ternary eutectic hercynite-fayalite-wuestite shows an even lower melting point of $1148^{\circ} \mathrm{C}$. Due to their ability to form silicates, Si and Mn can interact with each other, which makes them appear at the same locations in the scale. Si and $\mathrm{Cr}$, however, do not form mixed oxides or compounds.

\section{Acknowledgments}

The authors would like to express their gratitude to voestalpine Stahl GmbH for the sample preparation, consultation and financial contribution.

\section{REFERENCES}

[1] Fukagawa T., Okada H. \& Maehara Y. (1994). Mechanism of Red Scale Defect Formation in Si-added Hot-rolled Steel Sheets. ISIJ International, 34(11), 906-911. Doi: https://doi.org/10.2355/ isijinternational.34.906.

[2] Hiratani T., Zaizen Y., Oda Y. \& Senda K. (2018). Investigation of the magnetic properties of Si-gradient steel sheet by comparison with 6.5\%Si steel sheet. AIP Advances 8, 056122. Doi: https://doi.org/10.1063/1.5007190.

[3] Levin E.M., Robbins C.R. \& McMurdie H.F. (1964). Phase Diagrams for Ceramists. Vol. 1. Columbus, Ohio: The American Ceramic Society.

[4] Mouayd A.A., Koltsov A., Sutter E. \& Tribollet B. (2014). Effect of silicon content in steel and oxidation temperature on scale growth and morphology. Materials Chemistry and Physics, 143(3), 996-1004. Doi: https:/doi.org/10.1016/j.matchemphys. 2013.10.037.

[5] Praig V.G., Haubner R. \& Stöger-Pollach M. (2014). Microstructure and Composition of Grain Boundary- and Intragranular Oxides in Low Alloy Mn-Cr, Mn-Al-Si and Si-Al-P Hot-rolled Steel Sheets. Practical Metallography, 51(11), 785-799. Doi: https:// doi.org/10.3139/147.110175.

[6] Chen Y.R. (2020). Oversight or New Insight? Comments on Several Recent Papers Studying High-Temperature Oxidation of Si-Containing Steels. Oxidation of Metals, 93(1), 1-15. Doi: https://doi.org/10.1007/s11085-019-09947-5.

[7] Höfler T., Danninger H. \& Linder B. (2019). Examination of Oxide Scales Formed During Hot Rolling of Steels. Practical Metallography, 56(7), 449-456. Doi: https://doi.org/10.3139/ 147.110585.

[8] Caplan D. (1960). Overtemperature in Metal Scaling. Journal of The Electrochemical Society, 107(4), 359-360.

[9] Abuluwefa H., Guthrie R.I.L. \& Ajersch F. (1996). The effect of oxygen concentration on the oxidation of low-carbon steel in the temperature range 1000 to $1250^{\circ} \mathrm{C}$. Oxidation of Metals, 46(5), 423-440. Doi: https://doi.org/10.1007/BF01048639.

[10] Dollase W.A., Seifert F. \& O'Neill H.St.C. (1994). Structure of $\mathrm{Cr}_{2} \mathrm{SiO}_{4}$ and possible metal-metal interactions in crystal and melt. Physics and Chemistry of Minerals, 21, 104-109. Doi: https://doi.org/10.1007/BF00205221.

[11] Birks N., Meier G.H. \& Pettit F.S. (2006). Introduction to the High-Temperature Oxidation of Metals. ${ }^{\text {nd }}$ ed. Cambridge: Cambridge University Press, 111-112.

[12] Atkinson A. (1982). A theoretical analysis of the oxidation of Fe-Si alloys. Corrosion Science, 22(2), 87-102. Doi: https://doi. org/10.1016/0010-938X(82)90071-3. 